\title{
A proposta de um quadro norteador de pesquisa como exercício de construção do objeto de estudo
}

The proposal of a research guiding frame as exercise to construct the object of study

\section{La proposition d'un cadre directeur de recherche comme exercice de construction de l'objet d'étude}
La propuesta del cuadro orientador de investigación como ejercicio de construcción del objeto de estudio

Júlio Araújo*

(araujo@ufc.br)

\author{
Alcilene Aguiar Pimenta** \\ (alcilene.ufc@gmail.com) \\ Sayonara Costa* \\ (sayonaracosta@gmail.com)
}

Recebido em 17/06/2014; revisado e aprovado em 19/09/2014; aceito em 23/10/2014

DOI: http://dx.doi.org/10.1590/1518-70122015115

\begin{abstract}
Resumo: Nosso estudo incide sobre a aplicação de uma proposta didática para o ensino gênero projeto de pesquisa, contemplando os vieses textual e epistemológico da sua elaboração. O quadro norteador da pesquisa (QNP) reúne e relaciona questões, hipóteses de trabalho e objetivos a serem alcançados, sistematizando a construção do objeto. Diante disso, nosso principal questionamento foi “Como a elaboração dos QNPs contribuiu para a construção do objeto de estudo?". Os resultados mostram que, com o auxílio dessa ferramenta, os alunos apresentaram maior facilidade em construir seus objetos de pesquisa e em elaborar os projetos.

Palavras-chave: Projetos de pesquisa. Construção do objeto. Quadro norteador de pesquisa.
\end{abstract}

Abstract: This study investigates the design, development and application of a Research Guiding Frame (RGF) to undergraduate students enrolled in a Reading and Writing Academic Texts class at the Federal University of Ceará. RGF is a tool that assembles student' research questions, hypotheses and objectives. The results showed that RGF helped students refine their research projects and academic writing skills.

Key words: Research projects. Research object. Research guiding frame.

Résumé: L'analyse se concentre sur l'application d'une proposition didactique pour l'enseignement du genre projets de recherche, passant par les biais textuels et épistémologiques de son élaboration. Le cadre directeur de recherche (CQD) reúnit les questions, hypothèses et objectifs à atteindre, et offre une direction de laquelle partiront les autres sections du projet. Ainsi, la question de base a été: Comment l'élaboration de ces cadres a-t-elle contribué à la construction de l'objet d'étude? Les résultats montrent que les étudiants ont eu plus de facilité dans la construction de leurs objets de recherche et des projets.

Mots-clés: Projets de recherche. Construction de l'objet. Cadre directeur de recherche.

Resumen: Nuestro estudio aborda la implementación de una propuesta didáctica para la enseñanza del género proyecto de investigación, incorporando las dimensiones textual y epistemológica de su elaboración. El cuadro orientador de investigación (QNP) reúne y relaciona cuestiones, hipótesis y objetivos, sistematizando la construcción del objeto. Así, nuestra principal pregunta fue “¿Cómo la elaboración del QNP contribuyó a la construcción del objeto de estudio?". Los resultados muestran que, con esta herramienta, los estudiantes tuvieron mayor facilidad en la construcción de sus objetos de investigación y el diseño de proyectos.

Palabras clave: Proyectos de investigación. Construcción de objeto. Cuadro orientador de investigación.

\section{Introdução}

O fazer acadêmico, assim como toda prática social, está organizado em etapas e procedimentos que, devido à sua recorrência e necessidade de padronização, são materializados em gêneros textuais. Por conta disso, a formação de um pesquisador passa também pela apreensão das rotinas textuais que organizam e medeiam esse fazer. Cursos de licenciatura e bacharelado incluem em suas grades curriculares disciplinas voltadas para a escrita, em cujos programas são contemplados gêneros como o artigo científico, o resumo acadêmico, a resenha e o projeto de pesquisa. Este último, sobre o qual recai o foco

\footnotetext{
* Universidade Federal do Ceará (UFC), Fortaleza, CE, Brasil.

** Membro do grupo de pesquisa Hiperged.
} 
do presente artigo, destaca-se por ser critério para ingresso em programas de pós-graduação e para concessão de financiamentos de pesquisas no meio acadêmico e corporativo. No que diz respeito à sua estrutura, esse importante gênero do discurso acadêmico deve apresentar com clareza o tema e sua delimitação; os objetivos gerais e específicos; a justificativa do empreendimento; o referencial teórico que dará base epistemológica aos objetivos traçados; a metodologia que permitirá o alcance dos objetivos e um cronograma que demonstre a organização temporal das atividades da pesquisa.

Para além das especificidades textuais e composicionais, o projeto de pesquisa pressupõe de seu autor a capacidade de pensar e delimitar o objeto sobre o qual incidirá o estudo. Esse viés epistemológico, embora caminhe lado a lado com a habilidade de escrita, alimentando-a, revela-se complexo e por vezes hermético para aqueles que dão os primeiros passos na vida acadêmica. Apesar de serem diversos os métodos e manuais voltados para a elaboração do projeto enquanto gênero textual, são escassas as ferramentas disponíveis para aqueles que desejam apropriar-se do exercício de pensar um objeto a ser pesquisado.

Com o intuito de contemplar a elaboração do projeto de pesquisa em seus vieses estrutural e epistemológico, foi apresentada, aos alunos da disciplina de Leitura e Produção de Textos Acadêmicos (LPTA) do curso de Letras da Universidade Federal do Ceará (UFC), a proposta de elaboração de um quadro por meio do qual os graduandos visualizassem suas questões norteadoras, hipóteses de trabalho e objetivos gerais e específicos a serem alcançados em suas futuras pesquisas. Essa metodologia simples, porém vigorosa, é designada de quadro norteador de pesquisa (QNP) e consiste, no contexto deste trabalho, em uma proposta didática usada para o ensino desse gênero acadêmico. Com base nisso, no presente artigo, procuramos responder à seguinte questão: "Como a elaboração dos QNPs contribuiu para a construção dos objetos de estudo dos alunos de LPTA?"

Para dar corpo à discussão, organizamos o texto da seguinte maneira. Discutiremos, em primeiro lugar, sobre a construção do objeto de pesquisa;depois, mostraremos nossas decisões metodológicas para, na sequência, apresentarmos a análise dos dados. Concluiremos o artigo com as discussões acerca dos resultados da análise.

\section{Descortinando a construção do objeto}

Ao nos debruçarmos sobre a literatura referente à elaboração de projetos e construção de objetos de pesquisa, é possível notar a estreita relação entre essas duas atividades, tão próximas e interdependentes e que, por vezes, ficam confusos os limites entre ambas. Essa peculiaridade pode gerar imprecisões, dificultando uma abordagem mais didática do assunto. Com o intuito de minimizar esses percalços, a seguir, apresentamos as seções do projeto de pesquisa, discutindo aquilo que cada uma delas demanda no que diz respeito à construção do objeto. Uma vez de posse dessas informações, explicaremos, na seção seguinte, como elas podem ser operacionalizadas pelo QNP.

A escolha do tema é o primeiro passo rumo à construção de um objeto de pesquisa. Independentemente de sua origem, o tema é, na fase inicial, necessariamente amplo, precisando bem o assunto geral sobre o qual se deseja realizar a pesquisa. Entretanto não se deve eleger temas exageradamente amplos, pois isso poderá inviabilizar o aprofundamento do exercício de investigação. É relevante lembrar que o trabalho será menos árduo se o tema se inserir em uma área do conhecimento que agrade o estudante. Feita a opção por determinado tema, é preciso que o aluno procure se inteirar a respeito das pesquisas já realizadas sobre ele, uma vez que não seria nada interessante pesquisar sobre um problema já abordado e solucionado. Umberto Eco (1995) sugere que um estudo deve dizer do objeto algo que ainda não foi dito ou rever sob uma ótica diferente o que já se disse. Além disso, o ideal é que uma pesquisa se desenvolva a partir de lacunas deixadas por outras, pois dificilmente haverá assunto totalmente esgotado. Portanto é importante que o pesquisador em formação se debruce sobre a literatura acerca do tema de seu interesse a fim de enlaçar argumentos que justifiquem a proposta que irá construir a partir desse levantamento.

O título, acompanhado ou não por subtítulo, difere do tema. O primeiro deve 
sintetizar o conteúdo da pesquisa, enquanto o segundo sofrerá um processo de delimitação e especificação, para tornar-se viável à pesquisa. A delimitação do tema é uma fase muito importante da construção do objeto, pois ela resvala na determinação do que será o problema foco da pesquisa. Ao proceder ao recorte do tema, o proponente deve ter clareza quanto aos limites geográficos, espaciais e sociais de sua proposta de trabalho. $\mathrm{O}$ problema deverá ser constituído a partir do tema proposto, esclarecendo a dificuldade específica com a qual nos defrontamos e que pretendemos resolver com a pesquisa.

A escolha do tema representa a demarcação de um campo de estudo dentro de uma grande área do conhecimento, logo sua delimitação significa um afunilamento em relação à visão geral do tema para, a partir disso, se fazer um questionamento. Esse movimento dará início à formulação do objetivo geral da pesquisa, que deverá dialogar intimamente com a questão norteadora do trabalho. Assim, para Rudio (2007), o objetivo predeterminado será a solução que se pretende alcançar para um determinado problema, é transformar o tema bem delimitado numa pergunta bem objetiva que deve ser respondida cientificamente.

Os objetivos específicos, por sua vez, terão a função de contribuir para o alcance do objetivo geral. Lakatos e Marconi (1995) asseveram que os objetivos específicos têm um caráter concreto. Desempenham uma função intermediária e instrumental, permitindo, de um lado, atingir o objetivo geral e, de outro, aplicar este a situações particulares. Desse modo, o objetivo geral apresentará verbos que indicarão o resultado pretendido: traçar, descrever, caracterizar, analisar, descobrir, explicar. À medida que os específicos terão verbos que servirão como indicação das metas no percurso até a obtenção do objetivo geral: enumerar, classificar, distinguir, selecionar e etc.

O próximo passo é a construção das hipóteses. Simplificadamente, hipóteses são as possíveis respostas a serem encontradas para os questionamentos do estudo, no entanto são apenas possibilidades, pois, da mesma maneira que podem ser confirmadas, poderão ser refutadas. Contudo um projeto de pesquisa só deve apresentar hipóteses de trabalho se for a intenção do proponente trabalhar com controle de variáveis. Em nosso trabalho na graduação, observamos que a maioria dos anteprojetos dos alunos aponta para pesquisas de caráter qualitativo. Sendo este o paradigma ao qual se filiara seus anteprojetos, a nossa orientação foi em outra direção, ou seja,

[...] as questões formuladas para a pesquisa não são estabelecidas a partir da operacionalização de variáveis, mas se orientam para a compreensão dos fenômenos em toda a sua compreensão, complexidade e em seu acontecer histórico [...] o processo de coleta de dados caracteriza-se pela ênfase na compreensão. (FREITAS, 2003, p. 27; grifos nossos).

Isto significa que os resultados devem ser apresentados de maneira descritiva e interpretativa - e não reduzidos a gráficos e tabelas, pois, como preconizam alguns manuais: "toda hipótese é o enunciado geral de relações entre pelo menos duas variáveis. Por sua vez, variável é o conceito que tem ou apresenta valores tais como: quantidades, qualidades, características, magnitudes, traços etc." (LAKATOS; MARCONI, 1992, p. 104).

Quando era o caso, sugeríamos aos alunos que substituíssem, em seus projetos, a palavra hipótese por suposição de trabalho, alegando que o foco de seus estudos não se reduziria a aspectos quantitativos. A suposição, embora introduza um dado hipotético, não possui um caráter controlador de variáveis, como postula o paradigma de pesquisa quantitativo. Assim, a depender das características dos anteprojetos, para evitar confusão epistemológica, a orientação dada aos alunos foi trabalhar com suposições de trabalho e não com hipóteses.

Conforme percebemos até aqui, a construção de um objeto de pesquisa requer, não apenas algum conhecimento prévio sobre o que se pretende pesquisar, mas, também, o domínio de algumas técnicas que garantirão o sucesso dessa construção. Como reflete Eco (1995, p. 21), "definir o objeto significa definir as condições sob as quais podemos falar, com base em certas regras que estabeleceram antes de nós". Entretanto, para graduandos iniciantes nas práticas discursivas acadêmicas, essa atividade é extremamente complexa, de modo que ensiná-los a produzir o gênero projeto de pesquisa, demanda um certo esforço didático por parte do professor e de seus bolsistas. É sobre esse aspecto que falaremos a seguir. 


\section{Aspectos metodológicos}

\subsection{Conhecendo a disciplina de LPTA e o contexto de uso do QNP}

A disciplina de LPTA integra o currículo do Curso de Letras da UFC como uma disciplina obrigatória cuja ementa aponta para "compreensão e produção de textos acadêmicos na perspectiva da metodologia científica e da análise de gêneros". A disciplina é ofertada para estudantes do segundo semestre do curso. Portanto eles ainda estão em fase de adaptação às rotinas acadêmicas, razão pela qual alguns se sentem limitados quanto à habilidade de produzir gêneros como o projeto de pesquisa, uma vez que construir um objeto de estudo exige conhecimento de algumas técnicas, de modo que, se o estudante não tiver um tema bem delimitado, poderá ter sua pesquisa inviabilizada.

Diante desse público, o objetivo de LPTA é oportunizar aos alunos situações didáticas por meio das quais seja possível “desenvolver habilidades de compreensão e produção de textos pertencentes a alguns dos gêneros mais praticados na esfera acadêmica. É uma disciplina relevante na formação do estudante de Letras, pois o domínio desses gêneros no uso efetivo da língua lhe possibilita atender as exigências dessa prática no contexto acadêmico" ${ }^{\prime 1}$.

No semestre 2011.1, a equipe de LPTA era formada pelo professor da disciplina, primeiro autor deste trabalho, de uma mestranda do Programa de Pós-Graduação em Linguística da UFC, e duas bolsistas de iniciação à docência, uma das quais é a segunda autora deste trabalho. Esta equipe se dividia nas tarefas didáticas de duas turmas de LPTA que funcionavam no período vespertino, com dois encontros semanais cada turma, além da interação virtual no fórum da disciplina ${ }^{2}$.

Pensando nas dificuldades vivenciadas pelos alunos, o primeiro autor deste artigo instituiu o QNP com o objetivo de consolidar didaticamente as questões, as suposições (ou hipóteses) de trabalho e os objetivos da

\footnotetext{
${ }^{1}$ Conferir <http://goo.gl/VmbBd3> [link reduzido pelo encurtador de links do Google].

${ }^{2}$ Criado em 2008 por Carla Poennia Gadelha Soares, então monitora da disciplina.
}

pesquisa, a fim de viabilizar um melhor desempenho por parte dos alunos ao desenvolver seus projetos. Evidentemente, o quadro não aparece no projeto de pesquisa, pois ele representa apenas uma metáfora visual da construção do objeto de pesquisa pretendido pelo estudante. Mas nossa prática mostrou que a elaboração do QNP, como exercício prévio à escrita da justificativa dos projetos e pesquisa, foi decisiva na construção do objeto de estudo dos alunos de LPTA.

Nossa experiência demonstra que, quando o aluno consegue chegar a um quadro como este mais ou menos organizado é porque tende a estar próximo de construir o seu objeto de pesquisa. Claro que essa construção não se encerra no quadro, já que ele representa apenas um exercício intelectual de elaboração daquilo que pretendemos estudar. Essa construção, no entanto, deve estar clara no texto de justificativa do projeto de pesquisa cujas urdiduras teórica e metodológica se permitirão flagráveis no texto em função da necessidade de fundamentar os objetivos a que o projeto se propõe alcançar. Nesse sentido, o leitor espera que cada um dos objetivos específicos sejam fundamentados teórico-metodologicamente. Esse movimento de construção do texto organiza, do ponto de vista composicional, o restante do projeto de pesquisa, que deve apresentar a fundamentação teórica para cada um dos objetivos específicos e um design metodológico por meio do qual o leitor perceba como o pesquisador em formação planeja alcançar a cada um deles. Para que o leitor veja o "rosto" do QNP, disponibilizamos, no anexo I, a figura 2 , retirada do fórum virtual de LPTA.

A 'apresentação' do quadro aos alunos dava-se em dois momentos: durante a aula presencial e, em seguida, no fórum virtual da disciplina. Nesses primeiros contatos, os alunos tomavam ciência do funcionamento da ferramenta, bem como da sua principal finalidade, que é possibilitar uma construção do objeto bem anterior à escrita do projeto. Assim, ao explicar aos alunos o que deve ser sistematizado dentro do QNP, todos saberiam que teriam que elaborar uma discussão teórica para suas questões, objetivos e suposições/ hipóteses de trabalho, bem como preparar uma metodologia que tornasse operativo o quadro de suas pesquisas. 


\subsection{Procedimentos}

Neste trabalho, optamos por uma abordagem descritivo-interpretativa, pois, com base nos dados, tracejamos esboços de como se deu o fenômeno de facilitação da aprendizagem dos alunos em relação ao gênero projeto de pesquisa através da atividade prévia do QNP e de que maneira esse quadro contribuiu para a construção do objeto.

Nessa investigação, foram observados 43 relatos postados no fórum virtual de LPTA. Além disso, procedemos à apreciação de 32 QNPs construídos pelos nossos alunos da graduação em Letras. Assim, tomamos como corpus de análise 43 fragmentos retirados da interação entre os alunos, o professor e sua equipe no fórum virtual da disciplina, e os 32 QNPs $^{3}$ construídos pelos estudantes. Para que a identidade dos alunos fosse preservada, usamos pseudônimos.

Para organização dos dados, salvamos telas do fórum por meio do recurso printscreen o que nos permitiu recortar do fórum virtual da disciplina os trechos relativos à discussão sobre o exercício de construção do objeto de pesquisa por meio do QNP. As categorias de análise a que chegamos acerca dos exercícios de elaboração de QNPs mostram que os alunos perceberam: 1) O significado da necessidade de um recorte para o tema; 2) Necessidade de fundamentação teórica para o elemento delimitado; 3) A relação entre questões, hipóteses e objetivos e 4) norte na escrita do projeto de pesquisa.

\section{Análise e discussão dos dados}

\subsection{Do significado da necessidade de um recorte para o tema}

Tendo nossa investigação o objetivo de analisar a influência do QNP na construção dos objetos de estudo tratados nos projetos de pesquisa desenvolvidos por alunos de LPTA,

\footnotetext{
${ }^{3}$ Ainda que, durante a disciplina e depois dela, tenhamos analisado o universo dos QNPs, que totaliza 32quadros, desenvolvidos pelos alunos de LPTA, não há possibilidade de anexarmos todos eles a este artigo. Assim, adiantamos que apontamos aqui apenas uma amostra constituída por três versões que representam os avanços dos alunos durante o exercício de criação de seus objetos de estudo.
}

começamos nossa análise a partir das interações ocorridas no fórum relativas ao tema e sua delimitação. ${ }^{4} \mathrm{Na}$ postagem exposta no anexo II, o professor convida os alunos a fazer o primeiro exercício rumo à construção do objeto de pesquisa, o que colaborou para que os alunos expusessem as dúvidas surgidas na hora de delimitar o tema das suas pesquisas.

Percebemos que, ao estimular os alunos a refletirem sobre seus temas, o professor tem em mente prepará-los para uma segunda atividade, a sistematização das ideias relativas às suas pesquisas em um quadro que funcionará como um norte no processo de elaboração dos projetos de pesquisa que eles desenvolveriam. Após o comentário do professor, Alice, uma das alunas, demonstra perceber que a escolha do tema e delimitação deste é o ponto inicial do projeto. "Não posso expor justificativas, objetivos e métodos para alcançá-los, sem antes saber o que vou pesquisar." Nesse fragmento, apesar de ela se confundir um pouco em relação a alguns conceitos, apresenta-se consciente quanto à importância da delimitação do tema. Entretanto, ao definir o tema do seu projeto, se estende: "Meu tema é competência informacional, quais habilidades disponho para utilizar a informação que recebo em meu benefício".

Ainda que os alunos sejam orientados em sala, nem sempre lembram de todos as orientações do professor, fato que, provavelmente, se repetiu com Alice, uma vez que o tema deve ser amplo e ter no máximo três palavras, pois deixamos as restrições para o momento da delimitação. Dessa forma, como sugere o professor no comentário posterior, seu tema poderia ser apenas: Competência informacional. Além disso, ele retoma a questão da relevância em fazermos leituras preliminares sobre o que pretendemos tomar como objeto de estudo: "O conceito de Competência informacional é trabalhado por qual autor? Já leu sobre esse conceito? Se apropriou dele?". Conclui suas indagações indicando um texto para que a aluna pudesse se informar um pouco mais sobre o assunto que pesquisaria.

Na sequência da discussão do fórum, surge o pedido de socorro de Joana. O tema da equipe dela era: "um estudo sobre as crenças relativas à fonética/fonologia do in-

\footnotetext{
${ }^{4}$ Ver anexo III
} 
glês construídas por alunos de letras da ufc". No entanto o grupo de Joana se mostrava confuso, sem saber como delimitar algo a partir disso. Diante do impasse, a mestranda procura ajudá-los, esclarecendo algo que já vem sendo observado desde o início de nossa análise. O tema deve ser curto e, de certa forma, abrangente. Explica que só a partir de um tema que atenda esses quesitos é que se passa à delimitação. Ela reforça que: “Depois de pensadas essas questões, vocês vão para o quadro norteador sistematizar suas ideias e elaborar os desdobramentos". Até aqui se observa que escolher e delimitar um tema é, para principiantes, algo bastante complicado, contudo essa árdua tarefa pode ser mitigada através das sugestões dadas pelo professor e por sua equipe.

\subsection{Necessidade de fundamentação teórica para o elemento delimitado}

Percebemos que nossos alunos ficavam agitados e sofriam pensando sobre quais autores deveriam ler para fundamentar teoricamente o recorte temático feito. Embora essa fase seja posterior ao QNP, muitos deles se anteciparam quanto a esse aspecto, e isto foi bastante proveitoso, como é observável na interação da figura $3^{5}$.

Lara expressa as dificuldades enfrentadas por sua equipe já no momento inicial do trabalho: "...estamos encontrando bastante dificuldades no tema e na sua delimitação". $\mathrm{O}$ trecho apresenta uma barreira que teve que ser quebrada, não apenas pelo grupo de Lara, mas pela maioria dos alunos que participaram dessa experiência. Uma das monitoras alerta a equipe sobre a importância de leituras prévias sobre a temática que desejam abordar, movimento enfatizado por Lakatos e Marconi (1992), e sugere a eles o link de um artigo que poderia ajudá-los quanto à delimitação, além de procurar fazê-los refletir sobre o conceito de interlíngua, assunto que pretendiam estudar. Por apresentarem essa preocupação com os elementos teóricos de seus trabalhos, os alunos já iam sendo orientados também nesse sentido. Desse modo, ao iniciarem a elaboração dos projetos, já tinham alguma base teórica sobre os elementos delimitados.
4.3 Da relação entre questões, hipóteses e objetivos.

O professor e sua equipe procuravam trabalhar em uma perspectiva didática de amadurecimento das ideias, de modo que os alunos das duas turmas de LPTA tiveram a oportunidade de entregar duas versões de seus trabalhos para correção. Além disso, podiam contar com o atendimento individual, nos horários disponibilizados pela monitoria e, também, como o apoio do fórum virtual, suporte relevante a essa disciplina. Veremos nas figuras 4, 5, 6 e 7 como se deu o processo de entendimento por parte dos alunos da relação entre questões, hipóteses e objetivos. Adotamos como exemplo o caso da evolução no processo de construção do objeto de estudo de um dos projetos elaborado pelas equipes. Analisamos, comparativamente, três versões de um QNP. A primeira foi postada no fórum, a segunda foi corrigida via email pela mestranda e a terceira foi impressa e entregue em sala de aula. Entretanto, antes disso, levamos em consideração os movimentos iniciais da equipe ao produzir a primeira dessas versões ${ }^{6}$.

Observamos que Jane confunde-se ao apresentar o objetivo geral da pesquisa como se fosse o tema, além de apresentar dúvidas quanto à abrangência da sua pesquisa. A mestranda a alerta quanto ao engano e a orienta em relação à abordagem dos assuntos que ela acredita que teria que falar, mas pergunta se realmente há a necessidade. A mestranda esclarece: "Quanto aos problemas citados, vocês só precisarão falar deles se eles realmente influenciarem na alfabetização e se estiverem relacionados à oralidade, caso não, ficam fora do escopo da pesquisa. Não é uma questão de extensão do trabalho, é a coerência dele." Diante do esclarecimento, Jane percebe a falha conceitual ejustifica-se numa outra postagem: "A del. do tema é: A influência da oralidade no processo da aprendizagem da escrita de crianças em idade de alfabetização. O que eu mandei acima como tema é na verdade a questão central....desculpe me atrapalhei".

É observável que no esboço do QNP postado por Jane, como vemos na figura 5 , já há um tema adequado e uma delimitação coerente. Fato resultante do trabalho didático 
do professor junto com sua equipe de apoio, além do esforço do próprio grupo de Jane, como demonstramos anteriormente. A questão central colocada nessa versão foi: "Como a oralidade influencia na escrita infantil?"; a hipótese geral seria: "A influência da oralidade na aprendizagem da escrita infantil possivelmente se dá pelo fato da criança ainda não ter uma consciência fonológica da língua materna em aprendizagem." E o objetivo geral proposto era: "Categorizar os tipos de inferência da oralidade na escrita das crianças". Percebemos que eles sistematizaram a primeira parte do QNP de maneira quase perfeita, pois transformaram a delimitação numa pergunta cientificamente respondível, ou seja, não bastaria um simples sim ou não. A hipótese apresentou-se como uma possível resposta à questão central, no entanto, expôs apenas um dos argumentos, de modo que essa parte sofrerá modificações na versão subsequente. O objetivo geral expressa o que pretendiam fazer para confirmar ou descartar a hipótese, então, sugerida. Aspecto que também evoluiu posteriormente.

Ao sair do fórum, o QNP ganha outro formato e se diferencia do modo exposto na figura 5. Observem que na figura 6 as questões, hipóteses e objetivos se encontram organizadas na estrutura física que o QNP realmente propõe. Nessa segunda versão, a questão central já aparece com uma sutil modificação, o que tornou a pergunta mais objetiva passando de: "Como a oralidade influencia na escrita infantil?", para: "Como a criança em fase de alfabetização faz uso da escrita?". Na hipótese geral faltava um dos argumentos que embasariam a justificativa da pesquisa, como aponta a mestranda, ao revisar essa versão que os alunos a enviaram por email. Vejamos na figura 7 como a equipe resolveu esse problema e, por fim, como ficou a terceira e última versão do QNP após esse longo processo de construção do objeto.

Na versão acima se tem uma hipótese mais bem formulada: "A influência da oralidade na aprendizagem da escrita pode ser flagrada através de marcas presentes nas produções infantis e se dá pelo fato de a criança ainda não ter uma consciência fonológica da língua materna em aprendizagem." O objetivo geral também deixava a desejar em alguns aspectos, vejam: "Descrever os usos da escrita das crianças em processo de alfabetização". Como ensinado em sala de aula, o objetivo geral deveria mostrar o fenômeno a ser analisado, bem como os argumentos que a nortearão. Apesar de já terem os dois argumentos: "a influência da oralidade e os fonemas que remetem aos problemas." , não haviam deixado isso claro, também, no objetivo geral. Após a instrução recebida o texto foi reformulado e na figura VII ficou assim: "Descrever os usos da escrita das crianças em processo de alfabetização, baseando-se na influência da oralidade causada pelo convívio familiar e social e pela não distinção fonológica.".

Nos desdobramentos, etapa do QNP em que devemos coordenar as questões, hipóteses e objetivos específicos, ou seja, sintetizar, em partes, os procedimentos que serão feitos para se alcançar o objetivo geral, a equipe de Jane também passou por um processo de maturação das ideias. Eles apresentaram duas questões específicas: "Que problemas relacionados à linguagem oral são flagrados na aprendizagem da escrita em crianças?" e; "Como as marcas da oralidade se deixam flagrar na escrita infantil?". A primeira hipótese específica é: "As crianças possuem algum transtorno de aprendizagem tais como troca e a supressão de letras e a hipercorreção.", estando relacionada logicamente com o primeiro objetivo da etapa de desdobramento; e a segunda: "As crianças, influenciadas pela oralidade e por falta de conhecimentos gramaticais, escrevem da mesma forma que ouvem." , por sua vez, ligada à questão específica dois. Fica claro quem para cada questão do desdobramentom há uma hipótese e, consequentemente, objetivos específicos. Na versão final do QNP que estamos analisando, ficaram os seguintes: "Mapear os tipos de influência da oralidade no processo de alfabetização das crianças" e; "Classificar os fonemas mobilizados pelas crianças que remeteriam a possíveis erros.".

Constatamos, através das três últimas figuras, que o nosso instrumento didático (o QNP) direciona bem a construção do objeto por parte dos alunos. Observamos, pelos quadros, que os alunos não vão para o preenchimento da segunda coluna sem antes pensar na primeira. E que o que está posto como questão central deve dialogar intimamente com a hipótese geral e o objetivo geral da pesquisa. 


\subsection{Do norte na escrita do projeto de pesquisa}

Notem que a equipe de Jane amadureceu a ideia inicial, delimitou um tema e, a partir disso, com a ajuda do QNP, conseguiu construir o objeto de pesquisa a ser trabalhado do projeto de pesquisa. Na figura 8, Jane faz um relato em que sintetiza a utilidade do QNP em relação à elaboração do projeto de pesquisa. Pedro, também aluno de LPTA, deu sua opinião sobre o QNP. O depoimento desses integrantes da turma confirma a suposição de que o QNP funciona como um facilitador no desenvolvimento de projetos de pesquisa, uma vez que, diante de um objeto de pesquisa bem construído, a atividade de produção desse gênero torna-se bem menos árdua.

\section{Considerações finais}

Ao longo deste artigo procuramos entender de que forma a elaboração dos QNPs pode contribuir para a construção do objeto de estudo dos alunos de LPTA, e de que maneira isso influenciou na elaboração do projeto de pesquisa. A análise dos dados nos permite constatar que o processo de construção do objeto foi bastante facilitado pelo uso do QNP. Apesar de termos detalhado neste trabalho a evolução de apenas um dos casos, foram analisados grande parte dos QNPs desenvolvidos pelos alunos das duas turmas de LPTA.

Percebemos que a maioria dos estudantes apresentou dificuldades semelhantes durante esse processo e que, de posse de QNPs bem elaborados, conseguiram desenvolver com segurança seus projetos de pesquisa, em especial, as seções: justificativa, fundamentação teórica e metodologia. Diante disso, acreditamos que o modelo didático para o ensino do gênero projeto de pesquisa aqui apresentado, o QNP, constitui-se numa ferramenta inovadora que contribuiu para a elaboração de bons projetos, podendo ser útil, não só aos aprendizes, mas também àqueles que já tenham experiência. Assim, a sistematização do objeto possibilitada pelo quadro norteador revela-se como um movimento inicial relevante à elaboração do gênero projeto de pesquisa.

Por fim, o uso do QNP no ensino do gênero projeto de pesquisa mostrou-se como uma metodologia eficaz que pode ajudar na instrumentalização dos alunos quanto aos saberes que precisam desenvolver acerca dessa atividade. Verificamos que o QNP apresentou-se como uma importante ferramenta, que deu suporte e maior segurança aos alunos durante o desenvolvimento das seções de seus projetos de pesquisa, pois tendo questões, hipóteses e objetivos bem definidos e expostos num quadro norteador, poderiam utilizá-lo para eventuais consultas sempre que se sentissem perdidos quanto ao foco da pesquisa.

\section{Referências}

BARROS, Aidil de Jesus Paes de; LEHFELD, Neide Aparecida de Souza. Projeto de pesquisa: propostas metodológicas. 8. ed. Petrópolis, RJ: Vozes, 1999.

BIANCHI, Álvaro. Pequeno e despretensioso guia sobre projeto de pesquisa. [s.d.]. Disponível em: <http:// pt.scribd.com/doc/5558145/Alvaro-Bianchi-Pequenoguia-Sobre-Projeto-De-Pesquisa\#scribd>. Acesso em: 25 jul. 2011.

BORBA, Siomara; PORTUGAL, Adriana Doyle; SILVA, Sérgio Rafael Barbosa da. Pesquisa em educação: A construção teórica do objeto. Ciência \& Cognição, Rio de Janeiro, v. 13, n. 1, p. 12-20, 2008. Disponível em: <http://www.cienciasecognicao.org/pdf/v13/cec v13-1_m318243.pdf> Acesso em: 22 jul. 2011.

ECO, Umberto. Como se faz uma tese. 12. ed. Tradução de Gilson César Cardoso Sousa. São Paulo: Perspectiva, 1995.

FREITAS, Maria Teresa.A perspectiva sócio-histórica: uma visão humana da construção do conhecimento. In. FREITAS, M. T.; SOUZA, S. J.; KRAMER, S. (Org.). Ciências humanas e pesquisa: leituras de Mikhail Bakhtin. São Paulo: Cortez, 2003. p. 26-38.

GIL, Antonio Carlos. Como elaborar projetos de pesquisa. 3. ed. São Paulo: Atlas, 1991.

GOLIATH, Paulo Henrique; SILVA, João Fernando Vieira da (Org.). 2008. Manual de elaboração de projetos de pesquisa. Disponível em: <http:/ / pt.slideshare.net/ jeffersoncostadesouza/11898884-manualdeelaboracaodeprojetodepesquisa>. Acesso em: 5 jul. 2011.

LAKATOS, Eva Maria; MARCONI, Marina de Andrade. Metodologia do trabalho científico.4. ed. São Paulo: Atlas, 1992.

MOTTA-ROTH, Désirée; HENDGES, Graciela Rabuske. Produção textual na universidade. São Paulo: Parábola, 2010.

RAUEN, Fábio José. Elementos de iniciação à pesquisa. Rio do Sul, SC: Nova Era, 1999.

RUDIO, Franz Victor. Introdução ao projeto de pesquisa científica. 34. ed. Petrópolis, RJ: Vozes, 2007.

SOARES, Carla Poennia Gadelha; ARAÚJO, Júlio César. $\mathrm{O}$ gênero E-fórum educacional e aprodução de texto acadêmico. In: COLÓQUIO SOBRE HIPERTEXTO, $1 .$, 2008. Anais... Fortaleza, CE: UFC, 2008. p. 115-122.

THIOLLENT, Michel. Metodologia da pesquisa - ação. 2. ed. São Paulo: Cortez, 1986. 
Anexo I

Quadro Norteador

por Sayonara Costa em Qui 07 Abr 2011, 22:38

\begin{tabular}{|l|c|c|}
\hline $\begin{array}{c}\text { QUESTÃO } \\
\text { CENTRAL }\end{array}$ & $\begin{array}{c}\text { HIPÓTESE } \\
\text { GERAL }\end{array}$ & OBJETIVO GERAL \\
\hline & \\
\hline \multicolumn{2}{|c|}{ DESDOBRAMENTOS } \\
\hline QUESTÕES & HIPÓTESES & $\begin{array}{c}\text { OBJETIVOS } \\
\text { ESPECÍFICOS }\end{array}$ \\
\hline & & \\
& & \\
\hline & & \\
& & \\
& & \\
\hline
\end{tabular}

Figura 1 - QNP no fórum virtual de LPTA 


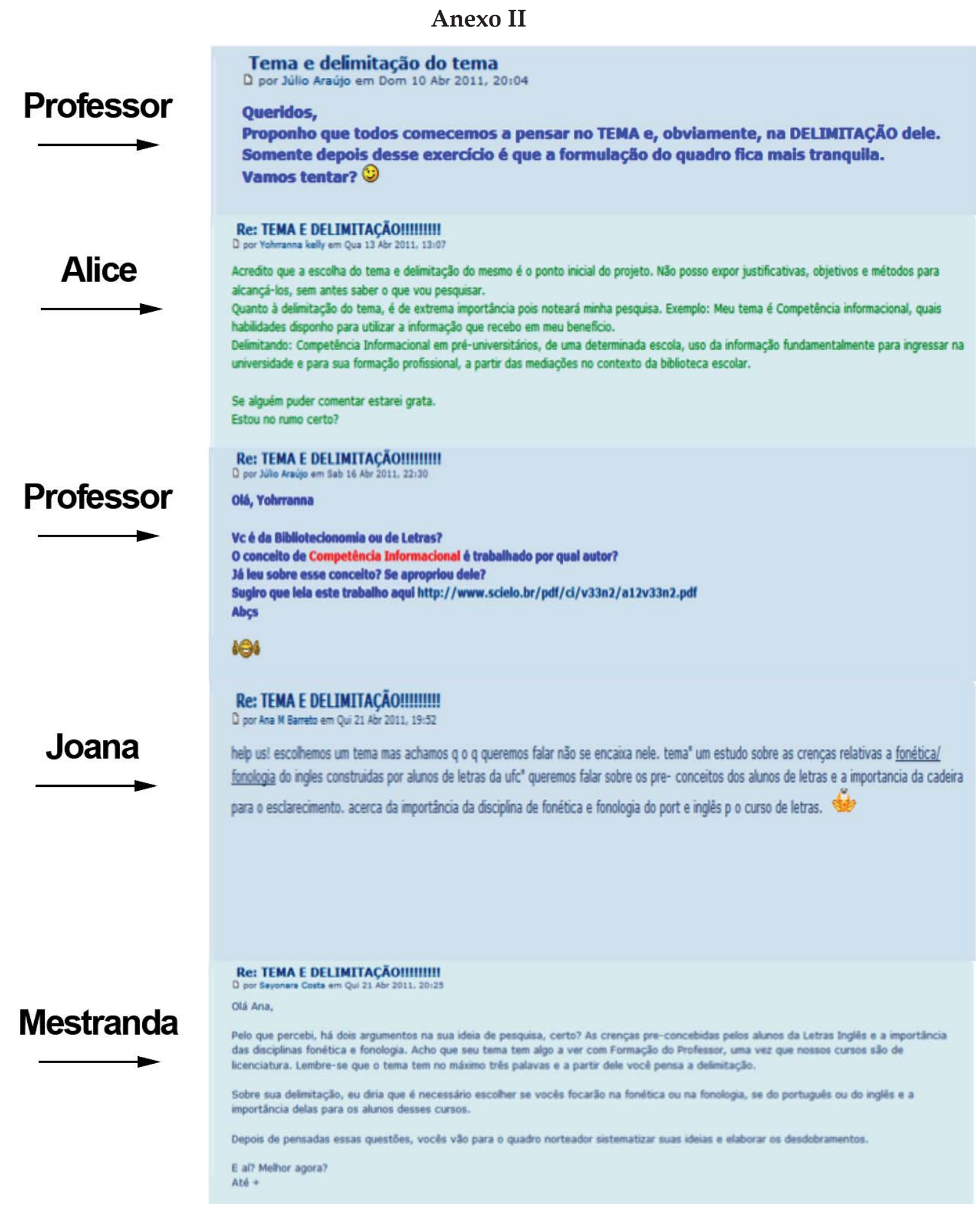

Figura 2 - Discussão sobre tema e delimitação do tema no fórum virtual 


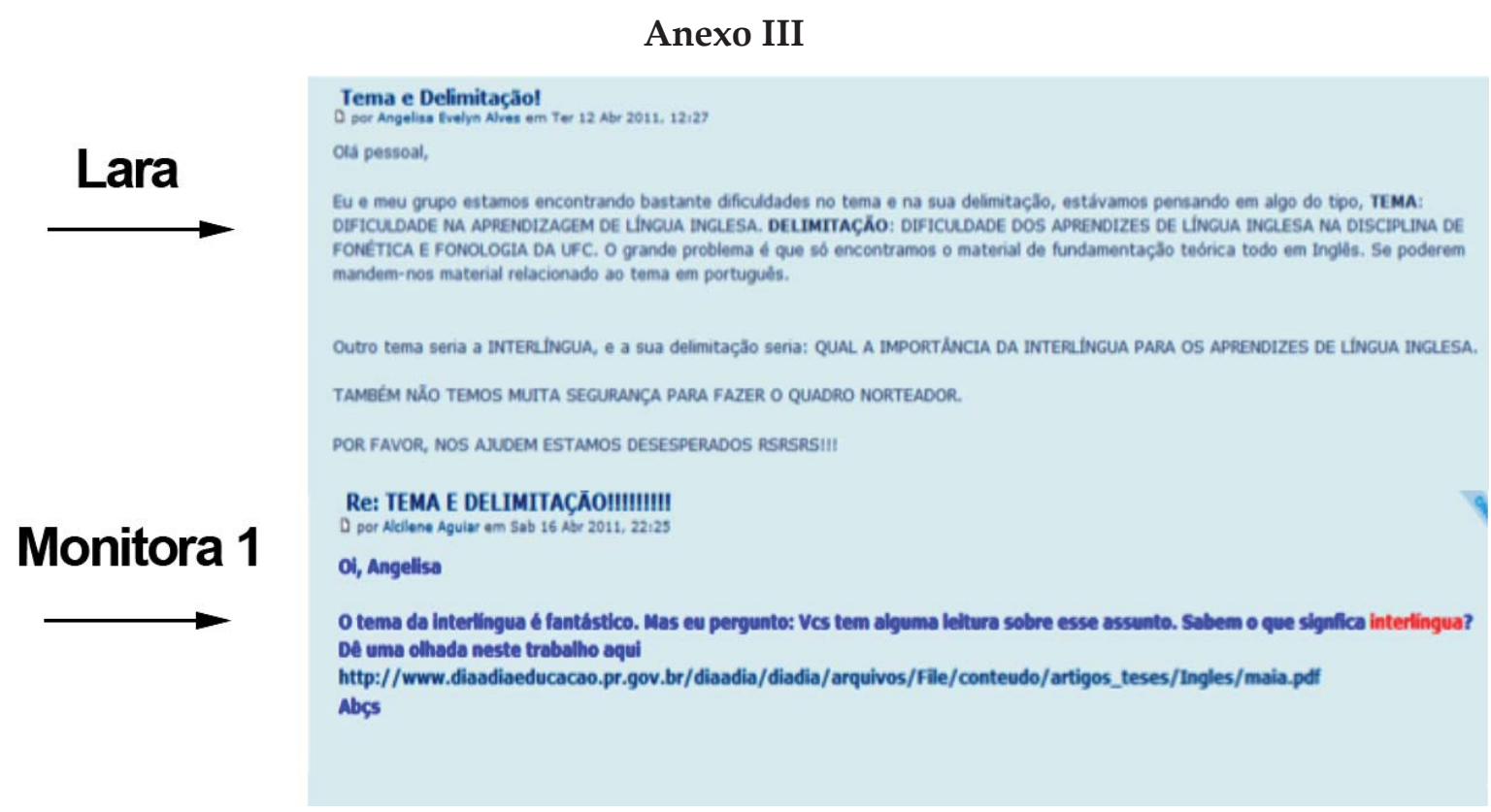

Figura 3 - Discussão sobre tema e delimitação do tema no fórum virtual

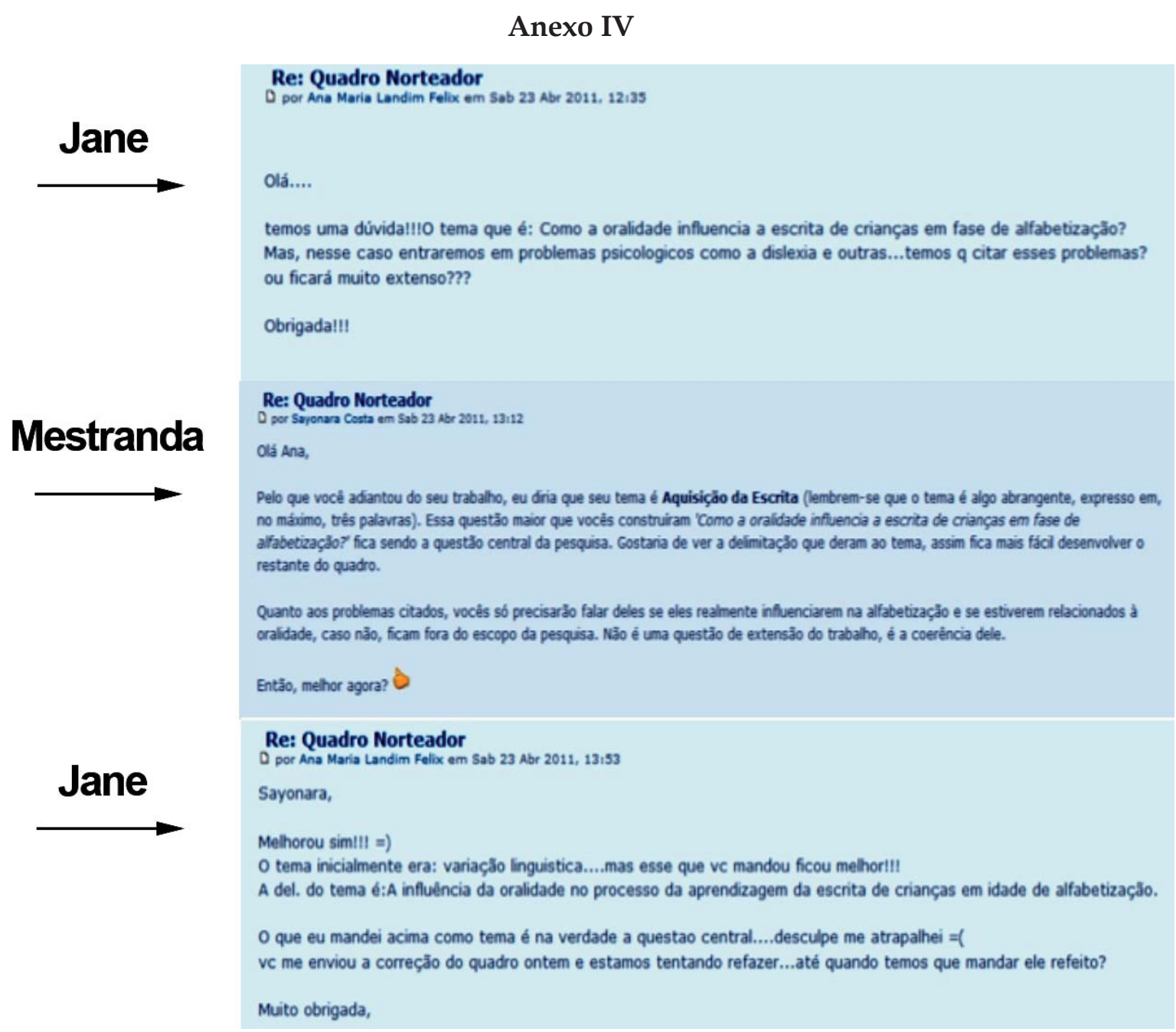

Figura 4 - Discussão sobre a elaboração do QNP 


\section{Anexo V}

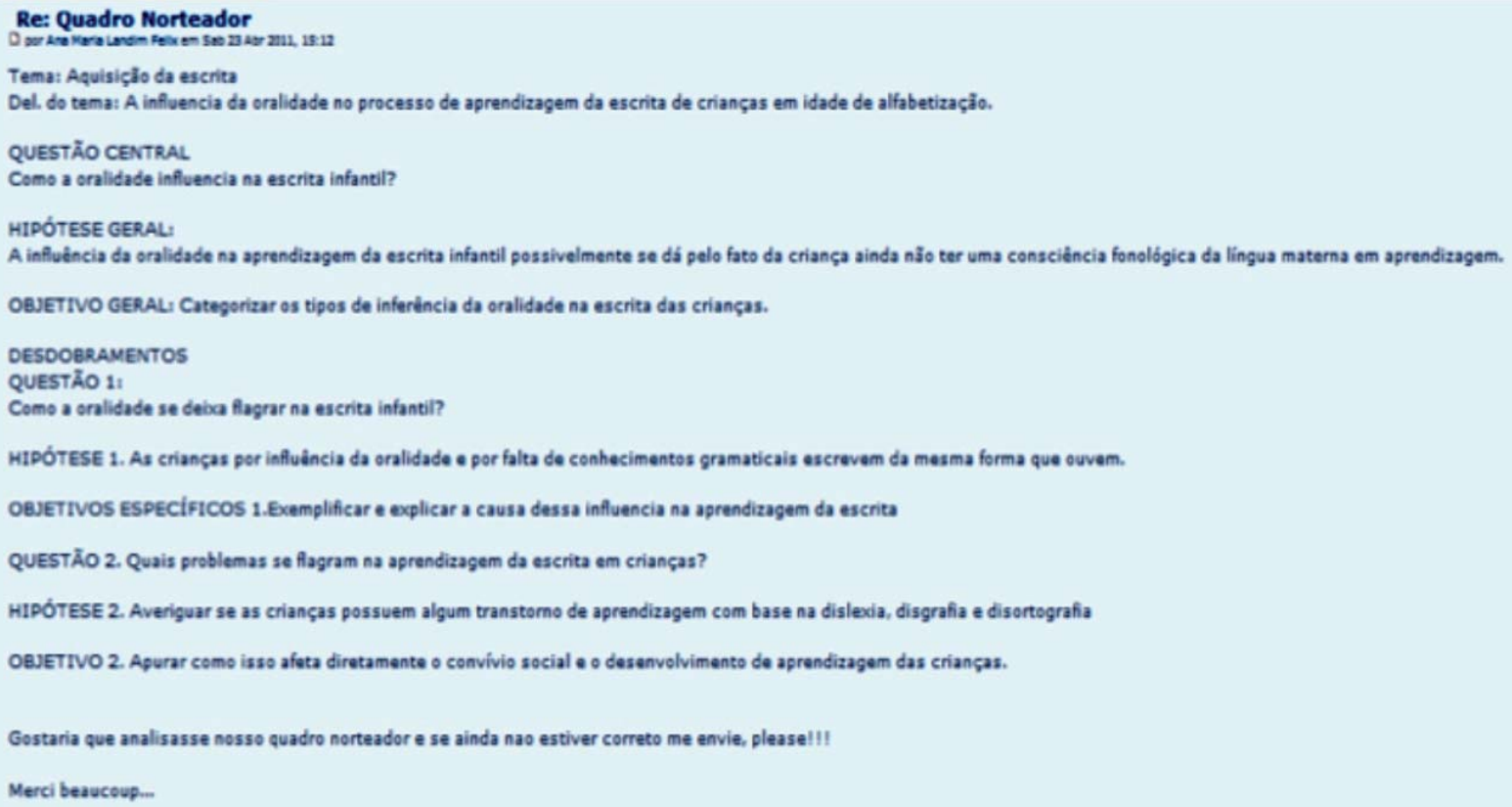

Figura 5 - $1^{\text {a }}$ versão do QNP

\section{Anexo VI}

TEMA. Aquisição da escrita

Del. Tema $\mathrm{A}$ influência da oralidade no processo da aprendizagem da escrita de crianças im idade de al fabetização.

\begin{tabular}{|c|c|c|c|}
\hline $\begin{array}{l}\text { QUESTAO } \\
\text { CENTRAL }\end{array}$ & $\begin{array}{l}\text { HIPOTESE } \\
\text { GERAL }\end{array}$ & $\begin{array}{c}\text { OBJETIVO } \\
\text { GERAL }\end{array}$ & \\
\hline $\begin{array}{l}\text { Como a criança em fase } \\
\text { de alfabetização faz uso } \\
\text { da escrita? }\end{array}$ & $\begin{array}{l}\text { A influência da oralidade na } \\
\text { aprendizagem da escrita } \\
\text { infantil se dá pelo fato da } \\
\text { criança ainda não ter uma } \\
\text { consciência fonoló gica da } \\
\text { língua materna em } \\
\text { aprendizagem } \downarrow\end{array}$ & $\begin{array}{l}\text { IDescrever os usos da escrita } \\
\text { das crianças em processo de } \\
\text { al fabetização }\end{array}$ & $\begin{array}{l}\text { [SC2] Comentários: Lembrem-se } \\
\text { que conforme o professor Júlio } \\
\text { expficou, o objetivo geral mostra o } \\
\text { fenomeno que sera analisado e os } \\
\text { argumentos que nortearâo a análise. } \\
\text { voces ja possuemos dois } \\
\text { argumentos, que sâo a influência da } \\
\text { oralidade e os fonemas que remetem } \\
\text { aos problemas. Precisam apenas } \\
\text { dizer isso também no objetiwo geral. }\end{array}$ \\
\hline & DESDOBRAMENTOS & & \\
\hline QUESTÕES & HIPÓTESES & $\begin{array}{c}\text { OBJETIVOS } \\
\text { ESPECIFICOS }\end{array}$ & $\begin{array}{l}\text { [SC1] Comentários: os argumentos } \\
\text { utilizados aparecem tambemna } \\
\text { justificativa. Coloquem-nos aqui. }\end{array}$ \\
\hline $\begin{array}{l}\text { Que probl emas } \\
\text { relacionados à linguagem } \\
\text { oral são flagrados na } \\
\text { aprendizagem da escrita } \\
\text { em crianças? }\end{array}$ & $\begin{array}{l}\text { As crianças possuem algum } \\
\text { transtorno de aprendizagem } \\
\text { ttais como nos basearemos } \\
\text { na troca de letra, supressão } \\
\text { de letras e hipercorreção? }\end{array}$ & $\begin{array}{l}\text { Map ear os tipos de } \\
\text { influência da oralidade no } \\
\text { processo de alfab etização } \\
\text { das crianças. }\end{array}$ & $\begin{array}{l}\text { [SC3] Comentários: ???? Acho que } \\
\text { precisaremos reescrever isso aqui, } \\
\text { de forma mais clara. }\end{array}$ \\
\hline $\begin{array}{l}\text { Como as marcas da } \\
\text { oralidade se deixam } \\
\text { flagrar na escrita infantil? }\end{array}$ & $\begin{array}{l}\text { As crianças, influenciadas } \\
\text { pela orali dade e por fal ta de } \\
\text { conhecimentos gramaticais, } \\
\text { escrevem da mesma forma } \\
\text { que ouvem. }\end{array}$ & $\begin{array}{l}\text { Classificar os fonemas } \\
\text { mobilizados pelas crianças } \\
\text { que remeteri am a possiveis } \\
\text { erros. }\end{array}$ & \\
\hline
\end{tabular}

Leitura e produção de textos acadêmicos

Figura 6 - $2^{\mathrm{a}}$ versão do QNP 


\section{Anexo VII}

TEMA: Aquisição da escrita

Del. Tema: A influência da oralidade no processo da aprendizagem da escrita de crianças em idade de alfabetização.

\begin{tabular}{|l|l|l|}
\hline \multicolumn{1}{|c|}{$\begin{array}{c}\text { QUESTÃO } \\
\text { CENTRAL }\end{array}$} & \multicolumn{1}{c|}{$\begin{array}{c}\text { HIPÓTESE } \\
\text { GERAL }\end{array}$} & \multicolumn{1}{c|}{$\begin{array}{c}\text { OBJETIVO } \\
\text { GERAL }\end{array}$} \\
\hline $\begin{array}{l}\text { Como a criança em fase } \\
\text { de alfabetização faz uso } \\
\text { da escrita? }\end{array}$ & $\begin{array}{l}\text { A influência da oralidade na } \\
\text { aprendizagem da escrita } \\
\text { pode ser flagrada através de } \\
\text { marcas presentes nas } \\
\text { produções infantis e se dá } \\
\text { pelo fato da criança ainda } \\
\text { não ter uma consciência } \\
\text { fonológica da língua } \\
\text { materna em aprendizagem. }\end{array}$ & $\begin{array}{l}\text { Descrever os usos da escrita } \\
\text { das crianças em processo de } \\
\text { alfabetização, baseando-se } \\
\text { na influência da oralidade } \\
\text { causada pelo convivio } \\
\text { familiar e social e pela não } \\
\text { distinção fonológica. }\end{array}$ \\
\hline \multicolumn{1}{|c|}{ QUESTÕES } & DESDOBRAMENTOS & \multicolumn{1}{c|}{$\begin{array}{c}\text { OBJETIVOS } \\
\text { ESPECÍFICOS }\end{array}$} \\
\hline $\begin{array}{l}\text { Que problemas } \\
\text { relacionados à linguagem } \\
\text { oral são flagrados na } \\
\text { aprendizagem da escrita } \\
\text { em crianças? }\end{array}$ & $\begin{array}{l}\text { As crianças possuem algum } \\
\text { transtorno de aprendizagem } \\
\text { tais como troca e a } \\
\text { supressão de letras e a } \\
\text { hipercorreção? }\end{array}$ & $\begin{array}{l}\text { Mapear os tipos de } \\
\text { influência da oralidade no } \\
\text { processo de alfabetização } \\
\text { das crianças. }\end{array}$ \\
\hline $\begin{array}{l}\text { Como as marcas da } \\
\text { oralidade se deixam } \\
\text { flagrar na escrita infantil? }\end{array}$ & $\begin{array}{l}\text { As crianças, influenciadas } \\
\text { pela oralidade e por falta de } \\
\text { conhecimentos gramaticais, } \\
\text { escrevem da mesma forma } \\
\text { que ouvem. }\end{array}$ & $\begin{array}{l}\text { Classificar os fonemas } \\
\text { mobilizados pelas crianças } \\
\text { que remeteriam a possíveis } \\
\text { erros. }\end{array}$ \\
\hline
\end{tabular}

Leitura e produção de textos acadêmicos

Figura 7 - $3^{\mathrm{a}}$ versão do QNP 


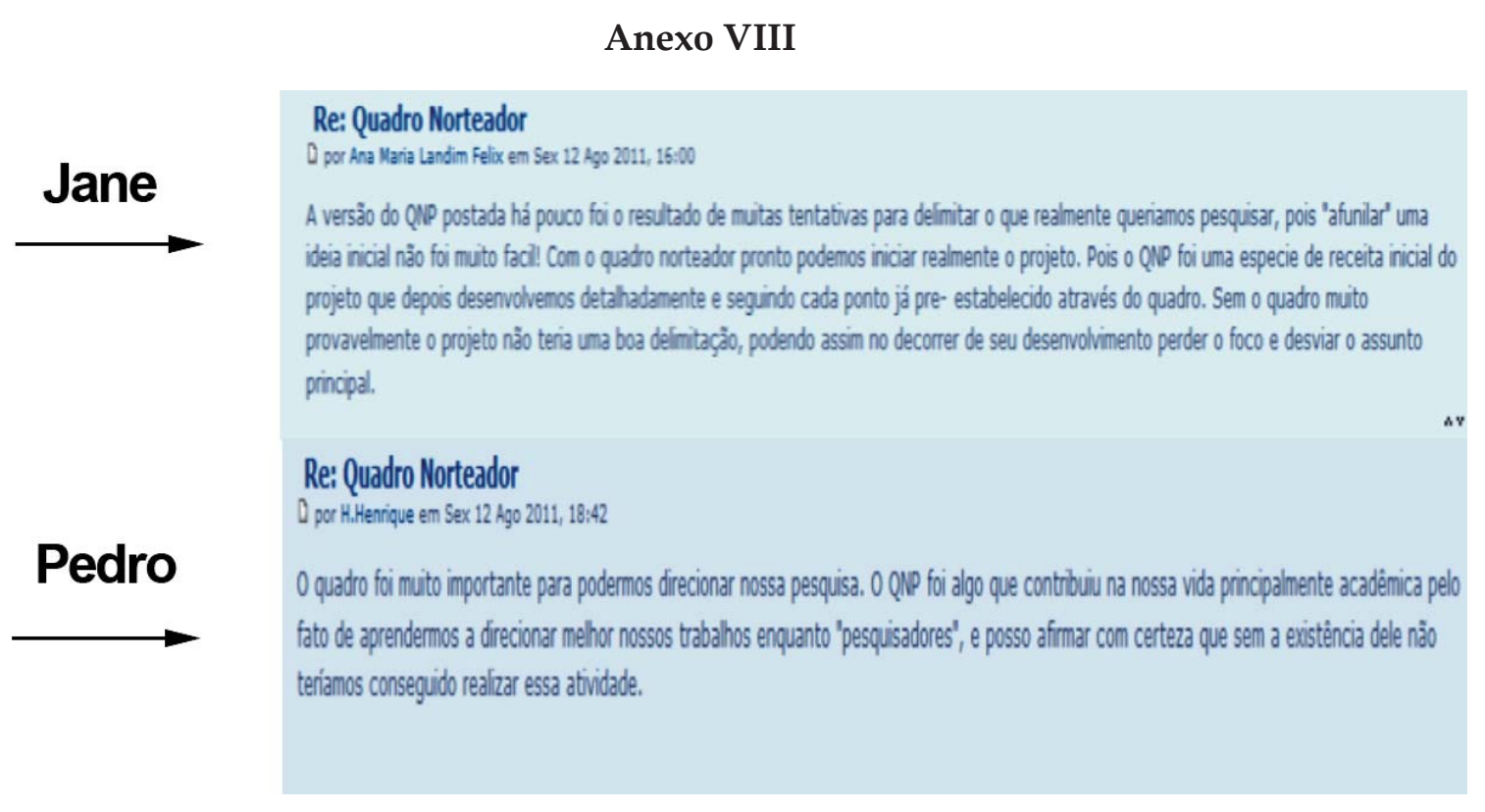

Figura 8 - Depoimento sobre a importância do QNP 